\title{
Molecular Epidemiology of Hepatitis C Virus and Predominant Genotype in India
}

\author{
Pushpalatha Manjunatha ${ }^{1,}$, , Satish Kumar Amarnath ${ }^{2}$, P. K. Menon ${ }^{3}$, Arun Kumar H. R. ${ }^{1}$, \\ Bala Satish M. ${ }^{1}$, S. J. Sabarish Babu ${ }^{1}$ \\ ${ }^{1}$ Central Laboratory, Whitefield, Bangalore \\ ${ }^{2}$ Head Quality, Compliance and Outreach Services, Manipal Cure and Care, Bangalore \\ ${ }^{3}$ Director, Center for Advanced Biomedical Research and Innovation, \& Professor Research, Gulf Medical University
}

Email address:

pushpa_micro@yahoo.com (P. Manjunatha)

\section{To cite this article:}

Pushpalatha Manjunatha, Satish Kumar Amarnath, P. K. Menon, Arun Kumar H. R., Bala Satish M., S. J. Sabarish Babu. Molecular Epidemiology of Hepatitis C Virus and Predominant Genotype in India. Clinical Medicine Research. Vol. 4, No. 5, 2015 , pp. $139-142$. doi: $10.11648 /$ j.cmr.20150405.13

\begin{abstract}
Analysis of the HCV genome has demonstrated extremely high heterogeneity in both structural and nonstructural coding regions and there are at least six different genotypes that have generally been divided into several subtypes. Of the 6 different Hepatitis genotypes, genotypes 1-3 is common worldwide, type 1a and $1 \mathrm{~b}$ are the most common, accounting for about $60 \%$ of global infections. They predominate in Northern Europe, Southern and Eastern Europe, North America, and Japan respectively. Type 2 is less frequently represented than type 1. Type 3 is endemic in south-east Asia and is variably distributed in different countries. The determination of the infecting genotype is important for the prediction of response to antiviral treatment; genotype 1 is generally associated with a poor response to interferon alone, unlike genotypes 2 and 3 which are associated with better responses. A total of 238 plasma samples were received from patients attending gastroenterology department across India for treatment from March 2008 - Aug 2010. The samples were analyzed for viral load by real time PCR by Taqman principle. HCV genotyping was carried out on the samples whose viral load was more than 300IU/ml (limit of detection as per the kit). Qiagen RNA columns were used for RNA extraction, followed by reverse transcription (Promega) and genotyping was performed by conventional PCR. Out of 238 samples, 117 were positive for 3a, 44 samples were load negative, 43 samples were non- typable due to less viral load i.e. less than $1000 \mathrm{IU} / \mathrm{ml}$. 26 were type 1a, 107 were $3 \mathrm{a}$, and 11 were $2 \mathrm{a}$.
\end{abstract}

Keywords: HCV, PCR, Reverse Transcription, Genotyping

\section{Introduction}

The genome of HCV is highly mutable. HCV being an RNA virus, lacks efficient proofreading ability as it replicates, virions infecting humans undergo evolution with time, giving rise to the notion that $\mathrm{HCV}$ persists as a collection of virus quasispecies (1).

The mutation occurs in hyper variable region of the genome coding for the envelope proteins and escapes immunity by the host and at the same time knocks host's innate immunity resulting in $\mathrm{HCV}$ chronic infection. Analysis of the HCV genome has demonstrated extremely high heterogeneity in both structural and nonstructural coding regions and has identified at least six different genotypes that have generally been divided into several subtypes. The development of vaccine for multiple serotypes is challenging for global use. The different genotypes show varied response to interferon/ribavirin combination therapy (2).

Hepatitis $\mathrm{C}$ virus (HCV) remains the major causative agent for parenterally transmitted non-A, non-B hepatitis. The detection of HCV RNA provides evidence of early and active infection. HCV qualitative and quantitative molecular tests and HCV genotyping tests have proved useful in making management decisions (3).

The development of vaccine for multiple serotypes is challenging for global use. The different genotypes show varied response to interferon/ribavirin combination therapy.

Hepatitis $\mathrm{C}$ virus (HCV) remains the major causative agent for parenterally transmitted non-A, non-B hepatitis. The detection of HCV RNA provides evidence of early and active $\mathrm{HCV}$ infection. Improvements in therapy have 
resulted in better virologic response rates, and $\mathrm{HCV}$ qualitative and quantitative molecular tests and $\mathrm{HCV}$ genotyping tests have proved useful in making management decisions (4).

$\mathrm{HCV}$ genotype is the strongest foretelling factor for sustained virological response since patients with different $\mathrm{HCV}$ genotypes act in response differently to alpha interferon therapy. Solid evidence has been established that HCV genotype- 2 and genotype- 3 infected patents are more likely to have a sustained virological response (SVR) to anti-viral therapy than patients infected with genotype-1 $\mathrm{HCV}$ infections (5).

The global prevalence of $\mathrm{HCV}$ infection is (approximately 3\%) 170 million people. In the United States, approximately 3.9 million people $(1.8 \%$ of the population) are positive for HCV antibodies.

The primary mode of HCV transmission is exposure to infected human blood via intravenous drug use or unscreened transfusions. The practice of screening donors for HCV antibodies in developed countries since 1990 has substantially lowered the risk of acquiring HCV infection from a transfusion to approximately 1 in 263,000 . This is based on results from nucleic amplification testing (NAT) of pooled donor samples that has been performed in the USA.

On the basis of its extensive genetic heterogeneity, HCV has been divided into six major genotypes (represented by Arabic numerals) and at least 80 subtypes (represented by lowercase letters). Different genotypes share approximately $65 \%$ sequence homology. Genotypes 1, 2, and 3 are found throughout the world; but the other genotypes are common in particular geographic regions (genotype 4 is common in North Africa and the Middle East, genotype 5 is common in South Africa, and genotype 6 is common in Southeast Asia). The predominant genotype in patients with chronic HCV infection in the United States is genotype 1 (72\% of patients), followed by genotype $2(16 \%)$ and genotype 3 $(10 \%)(6)$.

As per Gower et al., Genotype occurrence was available for ninety-eight countries, Globally, genotype 1 was the most common (46\%), followed by G3 (22\%), G2 (13\%), and G4 (13\%), (13)

The prevalence and number of HCV sero-positives have increased from $2.3 \%$ to $2.8 \%$ which is 122 million to $>185$ million between 1990 and 2005. Central and East Asia and North Africa/Middle East are estimated to have high prevalence. South and Southeast Asia, sub-Saharan Africa, Andean, Central, and Southern Latin America, Caribbean, Oceania, Australasia, and Central, Eastern, and Western Europe have moderate prevalence. Asia Pacific, Tropical Latin America, and North America have low prevalence $(<1.5 \%)$. (14)

HCV genotypes display significant differences in their global distribution and prevalence, making genotyping a useful method for determining the source of $\mathrm{HCV}$ transmission in an infected localized population. Quick and accurate genotyping of hepatitis $\mathrm{C}$ virus (HCV) is becoming increasingly important for clinical management of chronic infection and as an epidemiological marker (7).

The prevalence and distribution of $\mathrm{HCV}$ genotypes depend on geographical location. Three broad patterns of genotype distribution have been identified to date. One pattern, characterized by high genetic diversity, involves geographically discrete areas of West Africa with types 1 and 2, Central Africa with type 4 and Asia with types 3 and 6. This pattern is suggestive of a long period of endemic infection. Another pattern involves areas with a few subtypes circulating in specific risk groups, e.g., subtype 3a in drug addicts. The third pattern involves areas where a single subtype is present, such as in Egypt with subtype 4a and South Africa with subtype 5a (3).

Hepatitis $\mathrm{C}$ virus is one of the most important causes of chronic liver disease in the United States. It accounts for about $20 \%$ of acute viral hepatitis cases; $60 \%$ to $70 \%$ of chronic hepatitis cases; and $30 \%$ of cirrhosis, end-stage liver disease, and liver cancer cases. Seventy-five percent of HCV-infected individuals become persistently infected and many develop chronic hepatitis, which progresses eventually to liver cirrhosis and hepatocellular carcinoma (8).

Americans and Asians with $\mathrm{HCV}$ have a 2-fold and 4fold increased risk, respectively, of developing HCC when compared to Caucasians with HCV. The rate of chronic $\mathrm{HCV}$ infection is lower in patients who present with clinical symptoms such as jaundice during the acute onset of HCV infection as compared to those who do not have such symptoms. There have been extensive studies focusing on the natural course of disease progression from chronic hepatitis $\mathrm{C}$ to cirrhosis, hepatocellular carcinoma (HCC) and death (8).

\section{Materials and Methods}

A total of 238 plasma samples were analyzed from patients who had HCV infection referred to Manipal acunova central laboratory by Gastroenterologists across India from Jan 2007 to October 2010 from different states in India. Out of 238 patients 54 were females in the age group ranging from 5 to 70years with a mean age of 43.90 and std of 15.94 and 184 were males in the age group ranging from 5 to 70 years with a mean age of 46.78 and stdev of 14.34. 10 patients were from Karnataka accounting to $4.2 \%$, followed by Andhra Pradesh 30 (12.6\%), New Delhi 156 (65.5\%) Punjab 26(10.9) West Bengal 6 (2.5\%) Chatisgarh $9(3.8 \%)$ and Tamil Nadu $1(0.4 \%)$. Diagnosis of HCV was made by detection anti HCV antibodies by ELISA method and rapid method.

The EDTA blood samples were shipped at $-20^{\circ} \mathrm{C}$, DNA extraction was done using Qiagen DNA columns. HCV quantification was performed prior to genotyping using Taqman assay, reagents were from Qiagen. Samples whose viral load was less than $300 \mathrm{IU} / \mathrm{ml}$ were not included for genotyping. The procedure was followed as per TOMOYOSHI OHNO et al. 1997(12). Reverse transcription kits were from Promega and the primers were from Sigma 
Aldrich, Bangalore.

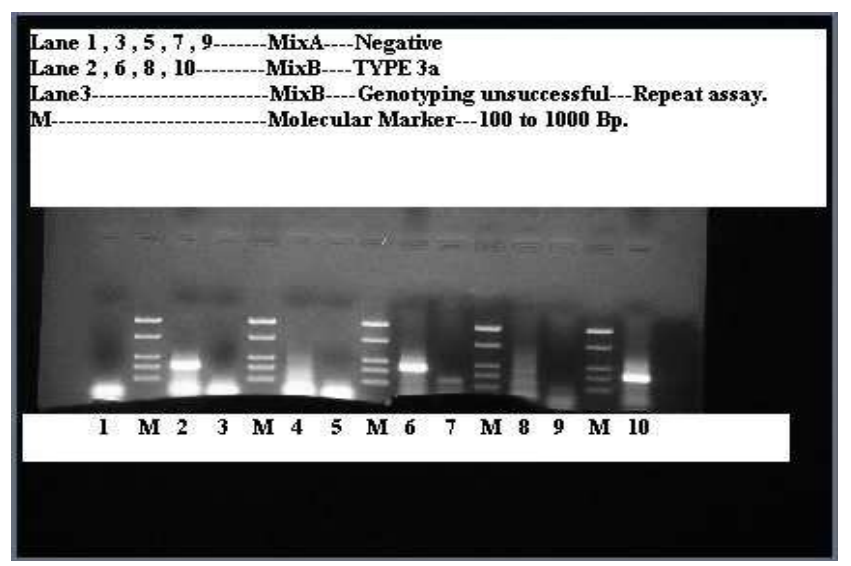

Fig. 1. Agarose Gel Electrophoresis of PCR products of different $\mathrm{HCV}$ genotypes

\section{Results}

Genotyping analysis was performed in 205 patients with positive anti-HCV and HCV-RNA. Out of 238 samples received for viral load in the age group ranging from $5 \mathrm{yrs}$ to
70 years of age, 184 were males, age ranging from 10 to 70 years, with a mean age of 41.78 , median of 42.0 and stdev of \pm 14.34 . Among the 54 females studied, the age range was $5 y$ rs to 70 years with a mean of 43.90 , median of 43.5 and stdev of \pm 15.94 .

Of the total 238, (156, 65.5\%) were from New Delhi followed by $(30,12.6 \%)$ from Andhra Pradesh, (26, 10.9\%) from Punjab, (10, 4.2\%) from Karnataka, (9, 3.8\%) from Chhattisgarh, $(6,2.5 \%)$ from West Bengal and $(1,0.4 \%)$ from Tamil Nadu.

Out of 238 samples 16 samples were negative for viral load i.e. less than the detection limit of the kit. Genotyping was negative in 17 samples as the minimum viral load required for successful genotyping is $1000 \mathrm{IU} / \mathrm{ml}$, kit detection limit being $300 \mathrm{IU} / \mathrm{ml}$.

Out of 206 in which genotyping was successful, a total of 145 were positive for $3 \mathrm{a}$ of which 104 males $3 \mathrm{a}$, and 36 females were positive for $3 \mathrm{a}$, followed by type 1a (18), $3 \mathrm{~b}(17), 2 \mathrm{a} \&$ 1a. Genotype $3 \mathrm{a}$ was uniformly distributed in all the states with a $p$ value of 0.0001 . 3a was the predominant genotype in both males and females which confirms there is no gender preference.

Table 1. HCV genotype distribution as determined by genotyping across India.

\begin{tabular}{|c|c|c|c|c|c|c|c|c|c|c|c|c|}
\hline State & $1 \mathrm{a}$ & $1 \mathrm{~b}$ & $2 a$ & $3 a$ & $3 b$ & $3 a \& 3 b$ & $1 a \& 2 a$ & 4 & 6 & NT & $\mathbf{N}$ & Total \\
\hline ND & 12 & 5 & 2 & 98 & 8 & 1 & 5 & 2 & 1 & 12 & 10 & 156 \\
\hline $\mathrm{AP}$ & 3 & 1 & 0 & 14 & 6 & 0 & 0 & 0 & 0 & 3 & 3 & 30 \\
\hline PJ & 2 & 1 & 0 & 13 & 2 & 2 & 1 & 0 & 0 & 2 & 3 & 26 \\
\hline KA & 1 & 0 & 0 & 8 & 0 & 0 & 1 & 0 & 0 & 0 & 0 & 10 \\
\hline CHAT & 0 & 0 & 0 & 8 & 0 & 0 & 1 & 0 & 0 & 0 & 0 & 9 \\
\hline WB & 0 & 0 & 0 & 4 & 1 & 0 & 1 & 0 & 0 & 0 & 0 & 6 \\
\hline $\mathrm{TN}$ & 0 & 1 & 0 & 0 & 0 & 0 & 0 & 0 & 0 & 0 & 0 & 0 \\
\hline
\end{tabular}

\section{Discussion}

The hypothesis of an Asian origin of HCV-3a relies on the large number of subtypes of HCV genotype 3 isolated in this area, suggesting several centuries of endemic presence of genotype 3 in Asian population (10).

Three HCV genotypes such as HCV-1, HCV-2, and HCV-3 have worldwide distribution and their relative prevalence varies from one geographic area to another. HCV-1a and $1 \mathrm{~b}$ subtypes are the most prevailing genotypes circulating in the United States of America and Europe. In Japan the most common circulating HCV subtype is $1 b$. HCV-2a and $2 b$ subtypes are mostly common in North America, Europe, and Japan. Subtype 2c is found commonly in northern Italy. $\mathrm{HCV}-4$ is the most prevalent genotype circulating in North Africa and the Middle East. HCV-5 and HCV-6 genotypes are established only in South Africa and Hong Kong, respectively (10).

The region used by Okamoto et al. for their type 3a primer might not be a suitable region for the design of primers if all the common subtypes were to be detected. As their system is based on the nucleotide sequences of genotype 1a, 1b, 1d, 2a, 2b, 3a, 3b, 4, 5a, and 6a HCV isolates, they believed that this system may have a much broader application. However, the number of samples of HCV types 3 to 6 tested was still not large enough for definitive conclusions to be drawn, which should be further tested in areas in which HCV types 3 to 6 are common to further validate this genotyping method. If the accuracy of our system is confirmed in these areas, this is a convenient and cost effective method and will assist research workers in conducting large-scale epidemiological studies.

In developed countries, in which donated blood is routinely screened for $\mathrm{HCV}$, infection control and safeinjection practices are in place, as well as in developing countries, injection drug use is an important risk factor for $\mathrm{HCV}$ transmission. Injection drug users have highest $\mathrm{HCV}$ sero -positivity rate in China. More than $80 \%$ of IDUs are sero-positive in Mexico, Pakistan, and Thailand. Egypt has the highest rate of hepatitis $\mathrm{C}$ in the world (10\%], (15).

The high prevalence of global HCV infection necessitates continuous efforts prevent primary infection, vaccine development, new approaches to secondary and tertiary prevention to reduce the burden of chronic liver disease and to improve survival for those who already have evidence of liver disease (14).

As per the KPK study, HCV genotypes $1 \mathrm{a}, 1 \mathrm{~b}, 3 \mathrm{a}$ and $3 \mathrm{~b}$ 
are distributed in various parts of KPK among which the genotype $3 \mathrm{a}$ is the most frequent genotype, our findings are similar to the above study(5).

\section{Conclusion}

We conclude that HCV genotypes $1 \mathrm{a}, 1 \mathrm{~b}, 3 \mathrm{a}$ and $3 \mathrm{~b}$ are distributed in various parts of India, $3 a$ being the most frequent genotype circulating in India.

\section{References}

[1] Ulrike Seifert, Heike Liermann, Vito Racanelli, Anne Halenius, Manfred Wiese, Heiner Wedemeyer, Thomas Ruppert, Kay Rispeter, Peter Henklein, Alice Sijts, Hartmut Hengel, Peter-M. Kloetzel and Barbara Reherm. Hepatitis C virus mutation affects proteasomal epitope processing. $J$ Clin Invest. 2004:114 (2):250-259.

[2] Houghton M. Hepatitis C viruses. In: Fields BN, Knipe DM, Howley PM, eds. Fields Virology, 3rd ed. Philadelphia, Lippincott - Raven, 1996:1035-105.

[3] Jean-Franc, ois Cantaloube, Pierre Gallian, Houssam Attoui, Philippe Biagini, Philippe De Micco, and Xavier de Lamballerie. Genotype Distribution and Molecular Epidemiology of Hepatitis C Virus in Blood Donors from Southeast France. Journal of Clinical Microbiology, Aug. 2005: 3624-3629.

[4] Yi-Wei Tang a,b, Haijing Li a, Ann Roberto c Diane Warner c, Belinda Yen-Lieberman. Detection of hepatitis $\mathrm{C}$ virus by a user-developed reverse transcriptase-PCR and use of amplification products for subsequent genotyping. Journal of Clinical Virology 2004, 31: 148-152.

[5] Amjad Ali1, Habib Ahmed, Muhammad Idrees. Molecular epidemiology of Hepatitis C virus genotypes in Khyber Pakhtoonkhaw of Pakistan. Virology Journal 2010: 7:203.

[6] Sandra S. Richter Journal Clinical Microbiology December 2002, vol. 40 no. 12 : $4407-4412$.

[7] Ping Qiu, Xiao-Yan Cai, Wei Ding, Qing Zhang, Ellie D
Norris and Jonathan R Greene HCV genotyping using statistical classification approach. Journal of Biomedical Science 2009, 16:62 doi:10.1186/1423-0127-16-62.

[8] Raymond P. Podzorski, PhD. Molecular Testing in the Diagnosis and Management of Hepatitis C Virus Infection. Arch Pathol Lab Med - 2002;126:285 - 290.

[9] Stephen L. Chen 12 and Timothy R. Morgan. The Natural History of Hepatitis C Virus (HCV) Infection Int J Med Sci. 2006; 3(2): $47-52$.

[10] Yoann Morice, Jean-Franc, ois Cantaloube, Ste'phanie Beaucourt, Laetitia Barbotte, Sija De Gendt, Fernando Lopes Goncales, Lesley Butterworth, Graham Cooksley, Robert G. Gish, Michel Beaugrand, Fabian Fay, Oscar Fay, Jorge E. Gonzalez, Regina Maria Bringel Martins, Daniel Dhumeaux, Bart Vanderborght, Lieven Stuyver, Erwin Sablon, Xavier de Lamballerie, and Jean-Michel Pawlotsky. Molecular Epidemiology of Hepatitis C Virus Subtype 3a in Injecting Drug Users.Journal of Medical Virology 2006, 78:1296-1303.

[11] S. Chaudhuria, S. Dasa, A. Chowdhuryc, A. Santrac,S.K. Bhattacharyab,d, T.N. Naik Molecular epidemiology of HCV infection among acute and chronic liver disease patients in Kolkata, India. Journal of Clinical Virology 2005, 32: 38-46.

[12] Tomoyoshi ohno, Masashi Mizokami, Rong-Rong Wu, Mohamed G. Saleh, Ken-Ichi ohba, Etsuro Orito, Motokazu Mukaide, Roger Williams, and Johnson Y. N. Lau. New Hepatitis C Virus (HCV) Genotyping System That Allows for Identification of HCV Genotypes 1a, 1b, 2a, 2b, 3a, 3b, 4, 5a, and 6a. Journal of Clinical Microbiology. Jan. 1997, Vol. 35, No. 1: 201-207.

[13] Gower E, Estes C, Blach S, Razavi-Shearer K, Razavi H. Global epidemiology and genotype distribution of the hepatitis C virus infection. J Hepatol. 2014 Nov;61(1 Suppl):S45-57.

[14] Mohd Hanafiah K, Groeger J, Flaxman AD, Wiersma ST. Global epidemiology of hepatitis $\mathrm{C}$ virus infection: new estimates of age-specific antibody to HCV seroprevalence. Hepatology. 2013 Apr;57(4):1333-42.

[15] Scott D. Holmberg, Hepatitis C Virus and the Infectious Diseases Community. Clinical Infectious Diseases 2012;55(S1):S10-15. 